\title{
How to Diagnose and Treat a Licorice-induced Syndrome with Findings Similar to that of Primary Hyperaldosteronism
}

Key words: licorice, primary hyperaldosteronism, 11ßHSD2, mineralocorticoid excess syndrome

Chronic ingestion of licorice or licorice-like compounds induces a syndrome with findings similar to that in primary hyperaldosteronism, namely hypertension, hypokalemia, metabolic alkalosis, low plasma renin activity (1). The only unique feature to this syndrome is that plasma aldosterone concentration is decreased. Since KM powder antacid (Towa Yakuhin Co. Ltd., Osaka, Japan ) contained licorice, chronic ingestion may induce this syndrome as shown in the case report by Ishiguchi et al (2).

See also p 59.

Initially, it was thought that the active component in licorice was a steroid, glycyrrhetinic acid. It was presumed that this compound had direct mineralocorticoid activity. However, it now appears that the major action of glycyrrhetinic acid is to inhibit the enzyme $11 \beta$-hydroxysteroid dehydrogenase, thereby allowing cortisol to act as the major endogenous mineralocorticoid (3-5). 11 $\beta$-hydroxysteroid dehydrogenase promotes the conversion of cortisol to cortisone, and one form of this enzyme (11 $\beta$-HSD2) is largely restricted in the kidney to the aldosterone-sensitive sites in the collecting tubules $(5,6)$. This effect is physiologically important, because cortisol binds as avidly as aldosterone to the mineralocorticoid receptor. Although cortisol has a much higher plasma concentration than aldosterone, it does not normally have much mineralocorticoid activity since it is locally converted to cortisone, a compound that does not bind to the mineralocorticoid receptor or to the collecting tubule glucocorticoid receptor which may also induce mineralocorticoid activity (6).

The treatment of this syndrome varies with the cause. Cessation of licorice is effective in patients ingesting glycyrrhetinic acid. In comparison, a potassium-sparing diuretic such as spironolactone and a low salt diet should correct the abnormalities in the syndrome of apparent mineralocorticoid excess.

Although the source of the ingested licorice may not be obvious, it is present, for example, in some forms of flavored chewing gum and chewing tobacco. Recently, Ishiguchi et al reported that KM powder contains licorice which may induce this syndrome (2). Actually, KM powder antacid is used as a digestant and contains $354 \mathrm{mg}$ of licorice and 900 $\mathrm{mg}$ of sodium bicarbonate per $3.9 \mathrm{~g}$ of powder. Usual dosage for adult is $3.9 \mathrm{~g}$ per day, 3 times after meal. Therefore, physicians should pay attention to the long-term administration of KM powder in patients with gastrointestinal disorders. Especially when the patient is in the volume depletion, it may stimulate bicarbonate reabsorption in the proximal tubules, resulting in the development of metabolic alkalosis.

In the case report by Ishiguchi et al, the authors suggested that metabolic alkalosis and hypomanesemia may be responsible for the etiology of myoclonus (2). However, there is no solid evidence for this. Symptomatic magnesium depletion is often associated with multiple biochemical abnormalities such as hypokalemia, hypocalcemia, and metabolic alkalosis. As a result, it is often difficult to ascribe specific clinical manifestations solely to hypomagnesemia. In 1960, 5 patients were reported with symptoms considered to be typical of magnesium depletion including tetany, positive Chvostek and Trousseau signs, and generalized convulsions (7). Somewhat similar findings such as generalized weakness, anorexia, hypokalemia, hypocalcemia, and positive Trousseau and Chvostek signs were noted when magnesium depletion was induced in normal volunteers (8). Tetany can occur in the absence of hypocalcemia and alkalosis and is presumably due to lowering of the threshold for nerve stimulation (9). Therefore, the causal relation between hypomagnesemia, metabolic alkalosis and myoclonus remain to be elucidated.

The diagnosis of metabolic alkalosis is usually evident from the history, as with vomiting, diuretic therapy, or diarrhea. In some cases, however, no cause is apparent. In this setting, the most likely diagnosis is surreptitious vomiting or diuretic therapy or one of the causes of mineralocorticoid excess (such as primary hyperaldosteronism, licorice induced mineralocorticoid excess syndrome). The first two disorders induce effective volume depletion, whereas hyperaldosteronism is usually associated with mild volume expansion due to the stimulatory effect of aldosterone on sodium reabsorption.

\footnotetext{
Eiji KusAno, MD, PhD Division of Nephrology, Department of Medicine, Jichi Medical School, 3311-1 Yakushiji, Minamikawachi, Tochigi 329-0498
} 


\section{References}

1) Farese RV Jr, Biglieri EG, Shackleton CH, Irony I, Gomez-Fontes R. Licorice-induced hypermineralocorticoidism. N Engl J Med 325: 12231237, 1991.

2) Ishiguchi T, Mikita N, Iwata T, et al. Myoclonus and metabolic alkalosis from licorice in antacid. Intern Med 43: 59-62, 2004.

3) Whorwood CB, Sheppard MC, Stewart PM. Licorice inhibits 11 betahydroxysteroid dehydrogenase messenger ribonucleic acid levels and potentiates glucocorticoid hormone action. Endocrinology 132: 22872292, 1993.

4) Morris DJ, Souness GW. Protective and specificity-conferring mechanisms of mineralocorticoid action. Am J Physiol 263: F759-F768, 1992.
5) Kenouch S, Coutry N, Farman N, Bonvalet JP. Multiple patterns of 11 beta-hydroxysteroid dehydrogenase catalytic activity along the mammalian nephron. Kidney Int 42: 56-60, 1992.

6) Funder JW. 11 beta-Hydroxysteroid dehydrogenase: new answers, new questions. Eur J Endocrinol 134: 267-268, 1996.

7) Nichols CG, Ho K, Hebert S. Mg (2+)-dependent inward rectification of ROMK1 potassium channels expressed in Xenopus oocytes. J Physiol (Lond) 476: 399-409, 1994.

8) Whang R, Whang DD, Ryan MP. Refractory potassium repletion. A consequence of magnesium deficiency. Arch Intern Med 152: 40-45, 1992.

9) Chase LR, Slatopolsky E. Secretion and metabolic efficacy of parthyroid hormone in patients with severe hypomagnesemia. J Clin Endocrinol Metab 38: 363-371, 1974. 